\title{
PRIMEIROS CAMINHOS, PRIMEIROS OLHARES
}

\author{
Maria Eunice de Souza Maciel \\ Universidade Federal do Rio Grande do Sul - Brasil
}

Resumo: Este texto procura sistematizar dados sobre os primeiros relatos e trabalhos de natureza etnográfica e antropológica envolvendo populações do Estado do Rio Grande do Sul, compreendendo o período anterior ao da criação da disciplina na UFRGS. Iniciando com as primeiras informações de europeus sobre as populações indígenas encontradas, segue com os relatos de estrangeiros e as contribuições dos chamados "eruditos locais".

Abstract: This article aims as systematizing data from the first reports and hooks involving populations from the state of Rio Grande do Sul, covering a period prior to the creation of the discipline of Anthropology at the Federal University of Rio Grande do Sul. Beginning with the first records by Europeans on indigenous populations, we follow up with a consideration on travel logs left by foreign visitors and, finally, the works of "local erudites".

\section{Introducão}

Este trabalho faz parte de um projeto institucional desenvolvido dentro do Programa de Pós-graduação em Antropologia Social da UFRGS a partir de 1990, Durante este período, o projeto contou com a colaboração de diversos pesquisadores que, em momentos distintos, integraram a equipe. O idealizador do projeto foi o professor Ruben George Oliven, que foi seu primeiro coordenador. Posteriormente, a coordenação ficou a cargo do professor Bernardo Lewgoy e, atualmente, está com a professora Maria Eunice Maciel. O projeto contou com o trabalho das antropólogas Sinara Robin e Lúcia Muller, numa fase inicial, e de diversos alunos, que contribuíram para o seu desenvolvimento. Entre o material já coletado encontram-se entrevistas com antigos professores, textos didáticos, fotos e filmes que constituem o início de um acervo sobre o tema que está, no momento, em fase de organização. 
O texto que segue é um breve roteiro, pontual e esquemático, procurando abordar o que poderia ser chamado de uma "pré-história” da antropologia no Rio Grande do Sul - o período anterior ao da criação da disciplina de Antropologia tanto na Universidade Federal do Rio Grande do Sul em 1942 como em outros centros de ensino. Trata de um período cujos documentos, trabalhos e obras citadas referem-se a uma problemática que remete às questões que envolvem a Antropologia mas não se trata, ainda, de um pensamento antropológico configurado (com o instrumental teórico e metodológico que caracteriza a investigação na área). Os dados aqui levantados possibilitam diferenciar perspectivas, a "exterior”, representada por aqueles que aqui estiveram mas que escrevem a partir de um referencial externo e a "interior", representada pelos "locais” que procuram entender o "local”.

Neste sentido, procura-se aqui esboçar, em grandes linhas, um roteiro preliminar e provisório da trajetória de um tipo de pensamento ligado à questões antropológicas na região. Como tal, o trabalho sofre de determinadas carências que mostram que está ainda no seu início mas que já podem ser apreciados alguns resultados, ainda que subsistam lacunas e omissões.

\section{Os primeiros registros}

Atualmente observa-se um interesse crescente pelos antigos relatos (escritos e pictóricos) - particularmente pelos efetuados por cronistas, viajantes e artistas que percorreram as terras brasileiras nos primeiros tempos de seu povoamento tais como os de Thevet (1557) ou de Léry (1578), relatos de viagens que influenciaram no pensamento europeu. ${ }^{1}$ Sobre este assunto, Ana Maria Belluzzo (1996, p. 10) assim coloca:

[...] No entanto, essas obras só podem dar a ver um Brasil pensado por outros. O olhar dos viajantes espelha, também, a condição de nos vermos pelos olhos deles. As obras configuradas pelos viajantes engendram uma história de pontos de vista, de distâncias entre modos de observação, de triangulações do olhar. Mais do que a vida e a paisagem americana, exigem que se focalize a espessa camada da representação. Evidenciam versões mais do que fatos. Na sua origem, as imagens elaboradas pelos viajantes participam da construção da identidade européia. Apontam modos como as culturas se olham e olham as outras, como

1 Ver Todorov (1989).

Horizontes Antropológicos, Porto Alegre, ano 3, n. 7, p. 215-231, nov. 1997 
estabelecem igualdades e desigualdades, como imaginam semelhanças e diferenças, como confrontam o mesmo e o outro.

Nicolau Sevcenko (1996, p. 108), ao refletir sobre a paisagem e a colonização do país mostra que dentro do processo de colonização é possível avaliar duas formas de percepção européia não dissociadas entre si mas que ao cabo tornam-se o que ele chama de "atitudes especializadas no contexto da evolução do processo colonizador”. São elas: o impulso desejante (desejo pelo desconhecido, vontade de conquistar) e a prática da intervenção colonizadora (agressiva).

Trazendo a reflexão para o sul do (hoje) Brasil, é interessante verificar a existência de documentos que tratam da ocupação deste território que se dá num período posterior ao dos chamados “viajantes” citados anteriormente, quando a colonização no nordeste e sudeste já se encontrava em franco desenvolvimento, e que o encontro com o indígena já está condicionado por estratégias desenvolvidas em outros lugares - em particular, a cruz e a espada.

De fato, a ocupação territorial do que viria a ser o Rio Grande do $\mathrm{Sul}^{2}$ é considerada pelos historiadores como tardia. Embora tenha sido descoberto a partir das expedições litorâneas da fase pré-colonizadora - registrado então como "Rio Grande de São Pedro" - não apresentava maior interesse, ficando assim inexplorado por mais de um século.

Foi no século XVII que iniciaram as primeiras expedições em direção ao sul e a ocupação da terra. Por um lado, pelo interior, este movimento foi feito pelos jesuítas espanhóis que fugiam dos ataques dos bandeirantes paulistas às suas reduções no território hoje paraguaio (ataques estes cujo objetivo era o apresamento de índios já aldeados), criando novas reduções no que viria a ser o Rio Grande do Sul.

Por outro lado, a Coroa portuguesa fundou, em 1680, face a Buenos Aires, a Colônia de Sacramento. Para garantir esta posse, era necessário ocupar as terras que situavam-se entre a Colônia e as povoações portuguesas no Brasil, o que foi feito a partir de expedições que tinham seu ponto de partida, principalmente, a partir de Laguna (no atual Estado de Santa Catarina). Em 1737, foi fundado o forte de Jesus-Maria-José, onde hoje está a cidade

2 Como estamos lidando com um período inicial, para fins de análise, os limites extrapolam o que hoje constitui o Rio Grande do Sul que nesta época era uma “terra de ninguém”. 
de Rio Grande, ponto fundamental para a ocupação portuguesa efetivar-se, já no seu início com um caráter militar próprio a uma zona de conflito entre dois poderios coloniais em expansão.

No entanto, desde muito antes o território era percorrido por indivíduos e grupos - os "gaudérios", mais tarde conhecidos por gaúchos - com o objetivo de caçar o gado que aqui tinha sido introduzido pelos jesuítas e que tinha se criado bravio.

Em decorrência da expansão jesuítica e da ocupação militar do território que hoje é o Rio Grande do Sul, os primeiros relatos são, principalmente, de militares e de religiosos. Agregam-se a estes os dos primeiros administradores e os dos chamados "viajantes". Os documentos deste período mostram uma “curiosidade” (que, em alguns casos, poderia ser chamada de "operacional”) em relação aos indígenas e sobre a terra, num primeiro momento e, num segundo, uma preocupação em informar sobre a sociedade que estava se constituindo.

Os primeiros registros mostram os encontros entre europeus (e/ou seus descendentes) e indígenas que habitavam a região. Conforme Guilhermino César (1981), uma das primeiras informações acerca das populações indígenas locais é 1605-1607. Trata-se do relato do padre Jerônimo Rodrigues descrevendo costumes dos índios Carijós e Araxás, habitantes da região nordeste do atual Rio Grande do Sul e o sudeste do atual Estado de Santa Catarina. Jerônimo Rodrigues era um jesuíta português que acompanhado pelo padre João Lobato saiu de Santos rumo ao sul pelo litoral, representando assim a primeira expedição jesuítica a estas terras, o que veio a ser chamado de "ciclo português”, encerrado com o regresso dos padres para o Rio. Segundo Luís Gonzaga Jaeger, ${ }^{3}$ o relatório do padre Jerônimo Rodrigues, escrito em Tramandaí, contava, entre outras coisas, o aprisionamento e venda dos indígenas como escravos, fato este que fazia com que esses fossem arredios ao contato, em particular os Araxás.

Porém, são os jesuítas espanhóis que marcaram fortemente sua presença no território, aldeando os indígenas do nordeste do território, os "TapesGuaranis" e assim originando, numa primeira fase, as chamadas "reduções” (povoações indígenas cristianizadas) e, numa segunda, os Sete Povos das

3 Cf. Jaeger (1956, p. 22). Segundo este autor, o relatório do padre Rodrigues foi publicado por S. Leite no vol. 194 da Brasiliana, p. 196-246. 
Missões. A primeira figura de destaque é a do padre Roque Gonzales de Santa Cruz, nascido em Assunção e conhecedor da língua Guarani o qual, segundo Jaeger (1956, p. 28) “[...] deixou-nos dessa porção do Rio Grande a primeira descrição geográfica, orográfica, potamográfica e etnográfica, referente ao ano de $1627 " .{ }^{4}$

Por outro lado, dentro do processo de ocupação militar da terra promovido pela Coroa Portuguesa, os relatos administrativos e militares se confundem. Neste caso, as informações são de outra natureza, mostrando os contatos, as articulações e as guerras que fizeram parte do processo de ocupação e apropriação desta zona fronteiriça disputada por duas potências européias. Neste sentido, mostram a utilização, em benefício do ocupante, de laços com determinados grupos indígenas e o aproveitamento das rivalidades intertribais pré-existentes, tal qual ocorreu em outras partes do Brasil, o que pode ser visto como "operacional”, ou seja, uma das estratégias utilizadas pelos colonizadores para dominar o território.

Como exemplo, podemos citar (também a partir de Guilhermino César, 1981) o relato de Francisco de Brito Peixoto, capitão - mor e um dos responsáveis pela colonização do Rio Grande do Sul que mostra as relações de amizade estabelecidas entre os portugueses e os índios Minuanos os quais seriam, posteriormente, aliados (e "bucha de canhão") nos conflitos com os espanhóis ou "castelhanos" (denominação genérica dos provenientes de regiões de colonização espanhola) pelo território. Outros relatos mostravam os conflitos entre os portugueses e populações indígenas como o que ocorreu entre os expedicionários de Silva Paes (considerado o fundador do Rio Grande) e os índios chamados de Tapes (Simão Pereira de Sá, 1737) ou ainda, os que relatavam os combates entre portugueses e guaranis (Manuel Martins dos Santos, 1755) durante as "guerras guaraníticas". Cabe salientar, nesta fase, um relato anônimo de 1749-1751 (escrito em italiano) sobre a catequese e aldeiamento de índios minuanos que descreve hábitos indígenas.

Se podemos dizer que existe algo que poderíamos chamar de "curiosidade” em relação ao indígena, ela se dá em decorrência dos objetivos da expansão européia, seja por parte dos projetos da Igreja (e, particularmente, da Companhia de Jesus), seja pela posse e ocupação da terra pela coroa

4 É de sua autoria também Os bem-aventurados Roque Gonzales, Afonso Rodriguez e João del Castillo, Livraria Selbach, Porto Alegre. 
portuguesa. Assim, aqui, num período de ocupação tardio em relação às primeiras expedições e aos primeiros contatos com a terra que veio a ser o Brasil, pode-se vislumbrar a ação inerente à expansão européia no que tange a um dado território - ocupando a terra, desalojando e até mesmo eliminando a população original. Porém, esta ação parte de uma determinada maneira de perceber as populações aqui encontradas e volta-se assim, à questão dos olhares, das maneiras de conceber o outro e a si mesmos.

\section{0 povoamento}

Com o povoamento, surge na região uma sociedade que aos poucos se estabelece com alguns contornos particulares, especialmente no que se refere à militarização. A tardia colonização fez com que o Rio Grande do Sul fosse povoado não apenas por portugueses vindos diretamente da metrópole mas, também e principalmente, por Ilhéus (açorianos) e pelos chamados "vicentinos” ou "lagunistas" (particularmente soldados), populações de origem portuguesa porém de áreas de povoamento já estabelecidas no Brasil. Assim, como em outras regiões, trata-se de um povoamento de desdobramento, já contando com misturas raciais e culturais. Junte-se a este fato a influência da colonização espanhola vizinha e esta região toma contornos que poderíamos chamar de "particulares" no que concerne ao Brasil.

Decorre daí um interesse em assinalar as características da região. Já em 1777, o cirurgião-mor de um regimento do Rio Grande do Sul, Francisco Ferreira de Souza, relata os costumes locais da população de origem européia que havia se estabelecido e elabora a primeira coleção de vocábulos e frases características da região sendo que suas apreciações são particularmente depreciativas em relação aos locais comparando-os com os europeus como segue:

Os Naturaes (não todos porem o comum) tem a mesma natureza do país, he gente ingrata, porca, dezagradecida, preguiçoza, e ambicioza; os que tem quatro cavallos, quarenta ou sincoenta vacas (por ser o gado barato) tem o seu equivaliente, e em cultivar a terra não cuidão: lassar, andar a cavallo, correr, fazer parelhas, e arreyar, hé o destino em que se empregão. Os Ilheos são os que (por ambiciozos) mais trabalhão, que por reduzirem a dinheiro toda a produção da terra e viveres, se sustentão de feijão, e abobra, os vestidos não passaao de hum pnxe, hu'a carniza grossa, e descalços (posto q'alguns não deixão de andarem mal calçados) brutalmente passão, brutam.e vivem, e brutamente 
morrem; as camas constão de hum Couro, e hum ponxe por abuzarem dos lançoes. (Souza, 1979, p. 246).

O interesse neste registro não é apenas decorrente do fato de ser um dos primeiros a descrever a população pertencente a sociedade que estava sendo constituída. Antes de tudo, mostra uma maneira de perceber e diferenciar-se dos que aqui viviam. A crítica aos "naturaes" e "ilhéus", ambos de descendência portuguesa (ou predominantemente) assim como português era o autor, mais do que revelar "estilos de vida", mostra apreciações capazes de estabelecer distinções e hierarquias. Aqui, trata de pensar a própria população de origem européia que, para usar sua palavra, se "brutaliza" no novo mundo.

\section{Outras viagens, outros diários e outras descrições}

No início do século XIX, já estabelecida a ocupação portuguesa (embora ainda houvesse conflitos de limites) salientam-se os registros de Auguste de Saint-Hilaire, cientista francês que percorreu o território em 1821 e deixou um estudo importante sobre a região, até hoje utilizado como referência. ${ }^{5}$ Sua contribuição vai deste a classificação da flora nativa (dentre a qual a erva-mate, Ilex paraguaiense) até mostrar um quadro sobre população local, tanto urbana quanto rural, descrita em seu diário.

Saint-Hilaire é um exemplo dos cientistas característicos desta fase: eruditos que realizam viagens para recolher informações e classificar tanto o que se refere às chamadas “ciências naturais” (botânica, zoologia, geologia, etc.) quanto o que se refere às populações encontradas nestas viagens numa perspectiva de ordem classificatória quanto ao novo e um olhar voltado para o exótico.

São desta época também as anotações de viagem de Arséne Isabelle (viagem entre 1833-34) ${ }^{6}$ e as descrições de Hormeyer (refere-se ao ano de 1850 mas escrita em 1853 e publicada em 1854 em Coblenz, Alemanha) e de Beschoren (1875-1887, editado em Berlim em 1889)7 sobre o território e seus habitantes. Hormeyer era militar e Beschoren, engenheiro.

\footnotetext{
Cf. Saint-Hilaire (1974)

Cf. Isabelle (1983).

Cf. Beschoren (1989).
} 
Escritos em suas línguas maternas, estes relatos se destinavam, principalmente, a informar a Europa e os europeus sobre as características desta terra, particularmente sobre as possibilidades de imigração, o que aparece como sendo uma preocupação importante e constante em seus trabalhos. A partir deste ponto de vista, muitas destas obras trazem dados gerais e detalhados sobre aspectos físicos, econômicos e, o que interessa mais precisamente, sobre a população local. Hormeyer tenta mesmo desfazer idéias que circulavam na Europa sobre a imigração alemã. Em suas palavras, pode-se verificar a perspectiva na qual escreve:

A intenção deste livro é, por enquanto, descrever uma região, conhecida pelo autor, conforme a verdade e a finalidade da emigração; tirar as consequências, fica a critério do leitor. [...] Também eu, um admirador do gênero humano em suas baixesas e grandezas, convencido dos incomensuráveis tesouros que o solo virginal do Brasil guarda em seu regaço para o trabalhador aplicado, pego, embora mais acostumado à espada, da pena, na esperança de me tornar útil ao país e aos meus patrícios. (Hormeyer, 1986, p. 15, 16).

\section{Os eruditos locais}

Já no século XIX iniciaram-se os estudos sobre a população local realizados por brasileiros ou por estrangeiros radicados no Rio Grande do Sul e cuja preocupação não se limitava a aspectos referentes às possibilidades imigratórias (embora em alguns estivesse também presente). Eram estudos embrionários, porém, já mostravam uma preocupações de certo cunho etnológico e lingüístico procurando detectar particularidades da sociedade aqui formada, ou seja, entram em jogo as diferenças. De certa forma, também representa uma busca pelo "pitoresco" e o "exótico" do território.

Um caso particular é o de Nicolau Dreys cuja obra foi editada em português em 1839/1840. Embora também contenha informações gerais sobre o território, tal como os estrangeiros anteriormente citados, Dreys viveu durante muitos anos no Rio Grande do Sul e sua obra, publicada durante a Revolução Farroupilha, não é, necessariamente, voltada para o exterior. E dele uma das descrições mais completas do grupo de gaúchos e dos rio-grandenses (com os quais estabelece distinções), utilizada até hoje por quem trabalha com o tema. Citando um breve extrato: 
[...] Tal é geralmente a distribuição da população em todo o Brasil; mas a província do Rio Grande oferece ainda a este respeito uma anomalia bem digna de se notar: é a existência de uma nação mista, intercalada entre as populações originárias e que pertence à raça livre, menos ainda por sua extração, do que pela possessão imemorial de uma liberdade indefinita que as leis das sociedades vizinhas podem dificilmente refrear; dizemos nação, por ter essa associação excepcional, moral, costumes e gostos sui-generis: entendemos falar dos gaúchos: expressão local a que não pretendemos das acepção nenhuma desfavorável; a esses homens consagraremos algumas linhas separadas. (Dreys, 1990, p. 109). ${ }^{8}$

Podemos citar o trabalho de Antonio Alvares Pereira Coruja que deixou uma obra constituída de crônicas e lembranças que mostram diversas faces da vida na Província tendo publicado o primeiro vocabulário regional, em 1852, a "Coleção de Vocábulos e Frases usadas na Província de São Pedro do Rio Grande do Sul.

Um destaque especial deve ser dado a Carlos Von Koseritz. Alemão de nascimento (nascido no ducado de Anhalt em 1830), Karl Von Koseritz veio ao Brasil quando muito jovem, com apenas 21 anos, estabelecendo-se no Rio Grande do Sul, casando com uma brasileira e naturalizando-se brasileiro.

Quando chega ao Brasil, já trazia na bagagem uma vida de aventuras tendo participado do movimento revolucionário de 1848 na Alemanha o que, segundo alguns, teria sido o motivo de sua vinda. Professor, jornalista, político, escritor, tornou-se figura de destaque e influência na vida intelectual e política da região.

Jornalista e escritor bilíngüe e anticlerical, Von Koseritz deixou uma vasta obra, em grande parte esparsa em artigos e crônicas. Entre suas obras estão: “A evolução do gênero humano” (1874/75), “A farsa dos Muckers na colônia alemã. Uma contribuição à história cultural dos alemães no Rio Grande do Sul” (1875) "Bilder aus Brasilien” (Imagens do Brasil, 1885) e "Bosquejos ethnológicos” (Koseritz, 1884). ${ }^{9}$ Nesta obra, que compõe-se de artigos publicados durante três anos na "Gazeta de Porto Alegre”, lamenta a perda (num incêndio) de sua coleção etnográfica, que reunia 15 anos de trabalho e pretendia figurar na Exposição Antropológica da corte. Compunha-se de mais de 2000 itens (material lítico e outros), objetos de uso dos indígenas da província Em outros artigos da mesma

8 Primeira edição possivelmente de 1839.

9 Cf. Spalding (1956, p. 197, 229). 
obra, fala dos sambaquis de Conceição do Arroio e de Cidreira como também da "hypothese phenícia" (discussão sobre a navegação do Amazonas e das costas do Brasil pelos fenícios, tese defendida pelo Barão de Tefé) (Koseritz, 1884).

Coletou lendas e poesias populares mantendo contato com Silvio Romero que cita seu trabalho nesta área como exemplo. Era partidário de Darwin, Haeckel, citava Lamarck e é por muitos considerado spenceriano. Dizia-se "franco adepto da escola de Jena, materialista científico, darwinista convencido". ${ }^{10}$ Sua principal obra sobre este assunto é "A Terra e o Homem à luz da moderna ciência” (1884) que reunia conferências de 1878.

Maçom, Von Koseritz combateu a Igreja Católica (os jesuítas em particular), os positivistas (que no Rio Grande do Sul vão ter uma grande importância política), os latifundiários (especialmente cafeicultores), a escravidão e os cônsules e enviados da Alemanha, o que the valeu inimizades poderosas. Embora tivesse grande orgulho de suas origens e tenha defendido e participado intensamente da vida das colônias alemãs, sua percepção era de uma participação na vida brasileira:

Os alemães do Rio são, a saber, estrangeiros; eles se interessam pelo Brasil e seus destinos somente quando estes coincidem com seus próprios interesses imediatos. Nós outros somos uma população de colonos e o centro de gravitação dos nossos interesses está no Brasil. Nós adquirimos a cidadania brasileira e compreendemos a necessidade de participar da vida política do país e adquirir influência para nos tornarmos respeitados. (Carneiro, 1959, p. 26).

Lutou pela imigração européia porém salientava que esta deveria ser feita através das colônias, núcleos baseados na pequena propriedade familiar e não como forma de suprir de mão de obra as grandes lavouras baseadas no latifúndio, em substituição ao braço escravo africano. Foi em função disso que bateu-se contra a imigração chinesa, em 1883, tentada por Tong - King - Sing, da China Merchant’s Steam Navigation Company. Estando no Rio de Janeiro, relata:

No que diz respeito ao interessante chinês, devo ainda ajuntar que ele chegou a três dias, tendo sido recebido com o maior entusiasmo pelos barões do café, de

${ }^{10}$ Cf. Carneiro (1959, p. 19). As informações aqui utilizadas baseiam-se, principalmente se bem que não exclusivamente, neste autor, seu principal biógrafo. 
tal maneira que no mesmo dia de sua chegada compareceu a um baile nos salões de conto de fada do palácio Haritoff com o qual Madame Haritoff encerrou a estação. Ali, naqueles salões dourados, onde corria em torrentes a champanha paga com o suor dos negros e nos quais a nata da sociedade daqui, que vive do trabalho dos negros, exibe o seu luxo, o mandarim foi naturalmente o herói do dia considerado como um Messias. [...] Nós declaramos guerra ao latifúndio e tentamos levar à vitória o sistema de pequenas propriedades, com a introdução de colonos agricultores. Os barões do café pretendem continuar a sua vida de vagabundos e se esforçam por isso na procura de novos escravos de cor amarela em substituição aos antigos pretos. ${ }^{11}$

Perseguido, Von Koseritz foi preso em 1890 e logo ao sair da prisão, faleceu. Sua vasta obra deixou marcos constituindo-se num referencial até hoje utilizado.

Ainda cabe citar, neste período, a figura de Apolinário Porto Alegre com trabalhos diversificados entre os quais incluem-se títulos tais como: "Morfologia Ario-guaranítica”, “Origens guarano-tupídicas”, "Popularium sul-riograndense” e "Origens Arianas do Guarano” e o trabalho de J. Romanguera Correa "Vocabulário Sul-Riograndense" de 1898. Cabe citar também o engenheiro francês Mabilde que deixou importantes anotações sobre os índios Coroados, com os quais teve contato durante o seu trabalho na região da serra.

Entre os "eruditos locais" da passagem do século XIX para o XX, destaca - se a obra de dois outros autores: o major Cezimbra Jacques e o padre Carlos Teschauer. Apesar do sobrenome francês, Cezimbra Jacques era neto de catarinenses, rio-grandenses e baianos, nascido em Santa Maria, RS. Representava assim uma via de colonização nitidamente luso-brasileira. Militar positivista, admirador de Augusto Comte, autodidata, Cezimbra Jacques deixou uma obra importante no que se refere ao Rio Grande do Sul, utilizada como referência até hoje. Conhecedor do território, muitas vezes percorrido em função de sua atividade, Cezimbra Jacques realizou estudos sobre os mais diversos assuntos tais como botânica, zoologia e geografia. No entanto, é em relação aos índios, (ao que consta, falava algumas línguas indígenas) e aos gaúchos (foi o fundador da primeira associação destinada a cultuar as tradições gaúchas no Rio Grande do Sul) e ao que chamaríamos de "folclore” (lendas, crendices, etc.) que seus estudos chamam a atenção.

${ }^{11}$ Artigo de 13 de outubro de 1883 (Carneiro, 1959, p. 32). 
Cezimbra Jacques foi um dos primeiros "locais” a pesquisar de maneira mais sistemática a própria terra porém, o que procurava era, de alguma forma, o "diferente", o que se encontrava em vias de extinção. No caso de Cezimbra Jacques se, em relação aos gaúchos, sua perspectiva era a de preservar suas tradições, em relação aos índios, era outra muito diferente. A partir das idéias de progresso e evolução do positivismo, pregava "incorporá-los à civilização”, propondo cruzamentos com os "nacionais, oriundos do ibérico” para "garantir o tipo nacional e evitar a anarquia que acarreta a fusão de muitas raças” (Cezimbra Jacques, 1979).

O padre jesuíta Carlos Teschauer, deixou também uma vasta e diversificada obra, na qual salientamos "Estudos Etnográficos sobre os principais achados índios no Museu de São Leopoldo” (1901), “A Etnografia do Brasil no princípio do século XX” (1915). Um de seus artigos sobre história e geografia do Rio Grande do Sul, é chamado de "Poranduba Riograndense ou Investigações sobre as origens do Estado de São Pedro do Rio Grande do Sul” (1929). Uma nota de rodapé informa que Poranduba é pergunta, inquirição ou noticia, vindo de uma conjunção de palavras em Tupi. Outro artigo do mesmo autor era "A língua guarani e o Ven. Pe. Roque Gonçalves ou Não compreendiam Bem os Jesuítas a Língua Indígena?” e “Avifauna e Flora nos Costumes, Superstições e Lendas Brasileiras” (1909-1910).

\section{Instituto Histórico e Geográfico do Rio Grande do Sul (IHGRGS)}

Um importante marco na produção intelectual da região, foi a criação do Instituto Histórico e Geográfico do Rio Grande do Sul - em 1921 - o qual congregou uma parte dos eruditos locais e editou uma revista que marcou toda uma fase de estudos na região.

O IHGRGS é uma criação tardia dentro do processo de associação de estudiosos nas diversas regiões do país decorrente da criação do Instituto Histórico e Geográfico Brasileiro em 1839. Sobre este assunto, assim se expressa Lilia Moritz Schwarcz (1993, p. 99-100) acerca do IHGB, o primeiro a ser criado, no Rio de Janeiro:

Criado logo após a independência política do país, o estabelecimento carioca cumpria o papel que lhe fora reservado, assim como aos demais institutos históricos: construir uma história da nação, recriar um passado, solidificar mitos 
de fundação, ordenar fatos buscando homogeneidade em personagens e eventos até então dispersos. Exemplos longínquos dos centros do Velho Mundo, no Brasil, os institutos se proporão a cumprir uma tarefa monumental: "Colligir, methodizar e guardar” (RIHGB, 1839/I) documentos, fatos e nomes para finalmente compor uma história nacional para este vasto país, carente de delimitações não só territoriais. [...]E, portanto, no interior desse processo de consolidação do Estado Nacional, tão marcado por disputas regionais, que toma força um programa de sistematização de uma história oficial. Ao IHGB coube o papel de demarcar espaços e ganhar respeitabilidade nacional. Aos demais, a função de garantir as suas especificidades regionais e buscar definir, quando possível, certa hegemonia cultural.

Caracterizando-se como uma sociedade regional voltada aos estudos, desde a sua criação o IHGRGS preocupou se com trabalhos de cunho etnográficos. Em seu estatuto (1921), já consta como objetivo "promover estudos e investigações que se relacionem com a História, Geographia, Archeologia, Ethnologia, Paleontologia do Brasil e especialmente do Rio Grande do Sul, e bem assim cultivar o folclore riograndense e a língua dos indígenas que habitaram e dos que ainda habitam este Estado". Entre as comissões permanentes do Instituto figuravam a de "Archeologia, Ethnografia e Paleontologia" e a de "Folclore e língua dos indígenas". ${ }^{12}$

Ao que parece, a visão que o Instituto tinha sobre etnologia era basicamente relacionada com o índio e, particularmente, sobre sua língua sendo que, em sua maioria, os autores não tinham contato com indígenas (salvo raras exceções) e seus estudos carecem de respaldo. Neste momento, não aparece uma separação clara entre áreas de conhecimento e pesquisa e assim, história, lingüística e etnolografia estavam mescladas e confundidas. A análise das publicações do Instituto de 1921 a 1929 mostra este aspecto, são vários os artigos que, de uma maneira ou de outra, tratam das línguas indígenas. Desde o primeiro número da revista, em 1921, são publicados artigos intitulados "Vocábulos Tupis na geographia riograndense", de autoria de Emilio Fernando Souza Docca, publicação esta que vai estender-se por muitos anos.

Mais adiante, inicia-se a publicação de outros temas, tais como as lendas riograndenses, de autoria de Roque Callage (em 1925), bem como um

${ }^{12}$ Revista do Instituto Histórico e Geográfico do Rio Grande do Sul, números de 1921 a 1929. 
Vocabulário Gaúcho do mesmo autor. Os estudos sobre a imigração, neste período, são raros. Em 1930 publicam a tradução de "Zehn Jahre in Brasilien" (de 1855) sobre a colonização alemã, de Carlos Seidler, ex-oficial ao serviço imperial brasileiro. Também o historiador Aurélio Porto interessou - se pelo tema e escreve em 1934 "Colono Alemão - Notas para a imprensa no Rio Grande do Sul” juntamente com "O Trabalho alemão no Rio Grande do Sul” que, em 1936, é publicado na revista “A colonização allemã no RGS” de Francisco Leonardo Truda. Posteriormente, Emílio Willems vai realizar pesquisas que resultaram em trabalhos cardinais sobre o tema como por exemplo "A aculturação dos alemães no Brasil. Estudo antropológico dos imigrantes alemães e seus descendentes”.

Sobre o negro, quase não há trabalhos no primeiro período. Em 1941 é publicada uma resenha do trabalho de Arthur Ramos feita por Fernando Goes mas é com Carlos Galvão Krebs e com Dante de Laytano em 1947 que os estudos nesta área serão realizados. ${ }^{13}$ Pesquisador, professor e, posteriormente, diretor do Instituto de Filosofia e Ciências Humanas da UFRGS, Dante de Laytano é uma das figuras de maior destaque na história da intelectualidade rio-grandense tendo pesquisado diversos temas mas especialmente a história e o folclore do Rio Grande do Sul e, o que nos interessa particularmente, sobre negros e religiões africanas.

Foi Dante de Laytano que recebeu e acompanhou Melville Herskovits e Roger Bastide em suas pesquisas no Rio Grande do Sul. E interessante notar que sempre que estas viagens são citadas, costumam ser chamadas de "visitas". De uma certa forma, mostra como eram encarados: visitas, ilustres, por certo, bem-vindos e afeiçoados também, porém passageiros. Ambos estavam estabelecidos em São Paulo (Herskovits entre 1941 - 42 e Bastide em 1943 - 46 - 47) e vinham ao sul para pesquisas que resultaram em trabalhos tais como "O batuque em Porto Alegre” (Bastide, 1959), “As congadas no sul do Brasil” (Bastide, 1947) e "Deuses africanos em Porto Alegre” (Herskovits, 1948). Ambos não apenas pesquisavam na região como também proferiam palestras e aulas. ${ }^{14}$ Pelo que pode ser levantado até o momento, Bastide (1948) contribuía também com artigos sobre outros temas como "A propósito da

\footnotetext{
13 Ver o artigo de Dayse Macedo de Barcellos nesta publicação.

14 Informação do professor Dante de Laytano.
} 
edição brasileira da Comédia Humana: Balzac, o homem e a obra” publicado na revista Província de São Pedro. ${ }^{15}$

Mas, voltando aos chamados “eruditos locais”, quem eram eles?

Eram militares, religiosos, professores, advogados, médicos, em suma profissionais de áreas diversas que, salvo exceções, não tinham na pesquisa sua ocupação principal. Eruditos no sentido de possuírem um conhecimento diversificado, formavam uma camada intelectualizada local. Em grande parte (senão em sua maioria) eram autodidatas no que se refere aos seus objetos de pesquisa - inclusive devido ao fato de não existir formação específica (pelo menos localmente). Embora possamos tentar classificá-los conforme suas orientações teóricas (positivistas, historicistas, etc.) cabe sublinhar que isto não exclui um autodidatismo que vai influir na perspectiva e no resultado de seus estudos. Assim, embora alguns de seus trabalhos sejam fontes de referência até hoje válidas, em boa parte são fragmentados e, seguidamente, apenas orientados pela busca de "sobrevivências" e "arcaísmos" ou então rastreando origens a partir do que era entendido como "folclore".

A sua própria definição era fragmentada, mostrando também a diversidade de assuntos sobre os quais se interessavam. Por exemplo (Ferreira Filho, 1958) Aurélio Porto é descrito como "poeta, jornalista, dramaturgo e historiador"; Apolinário Porto Alegre é que recebe a descrição mais extensa: "pedagogo, etnólogo, lingüista, crítico, dramaturgo, romancista, poeta, jornalista, filósofo, folclorista, antropólogo, teatrólogo, cronista, biógrafo, pensador”.

Polivalentes e autodidatas, muitos ainda mantinham as características dos eruditos de períodos anteriores interessando-se tanto pelas ciências naturais quanto pelas humanas. Um dos exemplos mais significativos foi o Padre Jesuíta Balduíno Rambo (também pertencente ao IHGRS) que deixou uma importante obra sobre os mais variados aspectos do Rio Grande do Sul (zoologia, geografia e, principalmente, botânica). No que se refere ao nosso tema em particular é com ele que nasce a disciplina de Antropologia e Etnolografia na Universidade Federal do Rio Grande do Sul em 1942. Mas esta já é uma outra história.

15 Esta publicação da Editora Globo criada em 1945 teve grande importância na vida intelectual da região. Embora de caráter regional, dedicava-se às letras e ciências humanas em geral publicando trabalhos de, por exemplo, Artur Ramos, Gilberto Freyre, Manuel Diégues Junior, Oliveira Viana, Emílio Willems, Antônio Cândido, Nelson Werneck Sodré, Sergio Buarque de Holanda e Helio Vianna. 


\section{Referências}

BASTIDE, R. As congadas do Sul do Brasil. Província de São Pedro, Porto Alegre, n. 10, 1947.

BASTIDE, R. A propósito da edição brasileira da Comédia Humana: Balzac, o homem e a obra. Província de São Pedro, Porto Alegre, n. 11, 1948.

BASTIDE, R. O Batuque em Porto Alegre. In: BASTIDE, R. Sociologia do folclore brasileiro. São Paulo: Anhembi, 1959.

BELLUZZO, A. M. A propósito d'O Brasil dos Viajantes. Revista USP, n. 30, Dossiê Brasil dos Viajantes, jun./jul./ago. 1996.

BESCHOREN, M. Impressões de Viagem na Provinda do Rio Grande do Sul 1875-1887. Porto Alegre: Martins Livreiro, 1989.

CARNEIRO, J. F. Karl von Koseritz. Porto Alegre: IEL, 1959.

CÉSAR, G. Primeiros cronistas do Rio Grande do Sul 1605-1801. Porto Alegre: Faculdade de Filosofia UFRGS, 1981.

CEZIMBRA JACQUES, J. Assuntos do Rio Grande do Sul. Porto Alegre: ERUS, 1979.

DREYS, N. Notícia descritiva da Província de São Pedro do Sul. Porto Alegre: Nova Dimensão: EDIPUCRS, 1990.

FERREIRA FILHO, A. Nomes tutelares do ensino riograndense. Porto Alegre: SEC, 1958.

HERSKOVITS, M. Deuses africanos em Porto Alegre. Província de São Pedro, Porto Alegre, n. 11, 1948.

HORMEYER, J. O Rio Grande do Sul de 1850: descrição da Província do Rio Grande do Sul no Brasil Meridional. Porto Alegre: D.C. Luzzato: EDUNISUL, 1986.

ISABELLE, A. Viagem ao Rio Grande do Sul. Porto Alegre: Martins Livreiro, 1983. 
JAEGER, L. G. Índios rio-grandenses civilizados pelos antigos jesuítas. In: ENCICLOPÉDIA RIO-GRANDENSE. Canoas: Regional, 1956.

SAINT-HILAIRE, A. Viagem ao Rio Grande do Sul - 1820-1821. Belo Horizonte: Itatiaia; São Paulo: USP, 1974.

SCHWARCZ, L. M. O espetáculo das raças. São Paulo: Companhia das Letras, 1993.

SEVCENKO, N. O front brasileiro na guerra verde: vegetais, colonialismo e cultura. Revista USP, n. 30, Dossiê Brasil dos Viajantes, jun./jul./ago. 1996.

SOUZA, F. F. de. Discripção a viagem do Rio Grande. In: ANAIS DO SIMPÓSIOCOMEMORATIVODOBICENTENÁRIODARESTAURAÇÃO DO RIO GRANDE (1776-1976). III volume. Rio de Janeiro: IHGB: IGHMB, 1979.

SPALDING, W. Itinerário da literatura sul-rio-grandense. In: ENCICLOPÉDIA RIO-GRANDENSE. Canoas: Regional, 1956.

TODOROV, T. Nous et les autres: la reflexion française sur la diversité humaine. Paris: Seuil, 1989.

VON KOSERITZ, C. Bosquejos ethnológicos. Porto Alegre: Typographia de Gunlach e Comp., 1884. 